Review

\title{
A review on the accuracy of bladder cancer detection methods
}

\author{
Chao-Zhe Zhu ${ }^{1}$, Hua-Nong Ting ${ }^{1 凶}$, Kwan-Hoong Ng$^{2}$, Teng-Aik Ong ${ }^{3}$ \\ 1. Department of Biomedical Engineering, Faculty of Engineering, University of Malaya, Kuala Lumpur, Malaysia \\ 2. Department of Biomedical Imaging, Faculty of Medicine, University of Malaya, Kuala Lumpur, Malaysia \\ 3. Department of Surgery, Faculty of Medicine, University of Malaya, Kuala Lumpur, Malaysia \\ $\triangle$ Corresponding author: Assoc. Prof. Dr. Hua-Nong TING, Department of Biomedical Engineering, Faculty of Engineering, University of Malaya, 50603 Kuala \\ Lumpur, Malaysia. Tel: +603-7967 6882; Fax: +603-79561378; Email: tinghn@um.edu.my. \\ (c) The author(s). This is an open access article distributed under the terms of the Creative Commons Attribution License (https://creativecommons.org/licenses/by/4.0/). \\ See http://ivyspring.com/terms for full terms and conditions.
}

Received: 2018.08.04; Accepted: 2019.04.28; Published: 2019.07.08

\begin{abstract}
Background and purpose: Bladder cancer is the most common malignant tumour in the urinary system, with a high incidence and recurrence rate. While the incidence of bladder cancer has been rising in recent years, the prevalence of bladder carcinoma is showing an increasing tendency in the younger age group. There are several methods to detect bladder cancer, but different methods have varying degrees of accuracy which intrinsically depends on the method's sensitivity and specificity. Our aim was to comprehensively summarize the current detection methods for bladder cancer based on the available literature, and at the same time, to find the best combination of different effective methods which can produce a high degree of accuracy in detecting the presence of cancerous cells in the bladder.
\end{abstract}

Materials and Methods: We used key word retrieval method for searching related references in English that had been indexed in PubMed and Medline.

Results and Discussion: This paper discussed the different detection methods and their sensitivities/specificities as well as the advantages and disadvantages. We summarized the best identified cancer cell detection methods with higher sensitivity/specificity.

Conclusion: The results of this review can positively help to identify accurate methods for detecting bladder cancer and highlight areas to be further improved for future research work.

Key words: Bladder cancer, Methods, Sensitivity, Specificity.

\section{Background}

Bladder cancer is the sixth most common disease in men and the seventeenth most common in women [1]. Its incidence ranks first among malignant cancers of the urinary system and second only to prostate cancer in Western countries. The pathologic histology shows that more than $90 \%$ bladder cancer patients have bladder transitional cell carcinoma, 5\% have bladder squamous cell carcinoma, and less than $2 \%$ have bladder adenocarcinoma [2]. Moreover, the incidence of bladder cancer is three to four times higher in men than in women $[3,4]$. Among patients who receive an initial diagnosis of bladder cancer, $70 \%$ to $85 \%$ have non-muscle-invasive bladder cancer
(NMIBC) and $15 \%$ to $30 \%$ have muscle-invasive bladder cancer (MIBC) [5]. NMIBC is known as superficial bladder cancer; its pathological stages include Ta (papillary), T1 (infiltration lamina propria), and carcinoma in situ. Ta patients comprise $70 \%$ of cases, $\mathrm{T} 1$ roughly $20 \%$ and carcinoma in situ about $10 \%$. MIBC is known as invasive bladder cancer; its pathological stages include T2, T3 and T4 $[5,6]$. Up to $80 \%$ of NMIBC patients relapse within 5 years; $30 \%$ of Ta patients progress to MIBC; while those with $\mathrm{T} 1$ and carcinoma in situ are more likely to develop MIBC [7, 8]. Transurethral resection is seen as a standard curative treatment for NMIBC, whilst radical 
cystectomy plus neoadjuvant chemotherapy is used to treat MIBC $[5,9]$.

The pathogenesis of bladder cancer is complex and multifactorial due to either intrinsic genetic factors or external environmental factors. Two major confirmed factors are smoking and prolonged exposure to aromatic amines. Smoking is the most confirmed pathogenic factor, as about $30 \%$ to $50 \%$ of bladder cancers can be ascribed to smoking, which can amplify the incidence of bladder cancer by two to four times. The incidence rate is in proportion to the intensity and duration of smoking. Haematuria is the earliest and most common symptom of primary bladder cancer. The nature of haematuria includes full-course, intermittent and painless gross haematuria, sometimes accompanied by blood clots $[8,10]$. Other clinical manifestations at the initial diagnosis include microscopic haematuria, lower urinary tract symptoms and urinary tract infection [11]. Statistics show that bladder cancer has high incidence, progression and recurrence rates. Therefore, in clinical work it is extremely important to accurately diagnose and assess patients with early bladder cancer and especially to monitor high-risk postoperative bladder cancer patients. The most common ways to diagnose bladder cancer include cystoscopy and biopsy, imaging methods, urinary cytology, fluorescence in situ hybridization, and urine protein detection (BTA-STAT, BTA-TRAK, NMP22 and ACCU-DX) [8, 12]. Urinary cytology and cystoscopy/biopsy are the current gold standard examination tools to diagnose bladder cancer. However, cystoscopy is an invasive examination and can cause pain, bleeding, urinary tract infections and other complications. In addition, it is sometimes difficult for cystoscopy to detect tumours in secluded corners of the bladder, which constrains its clinical application. Cytology is a non-invasive test that can directly identify tumour cells shed in the urine. It is simple to use and inexpensive and performs well, although it has low sensitivity and low diagnostic efficiency, especially with low-grade bladder cancer.

\section{Materials and Methods}

This study used the keyword information retrieval method. References related to bladder cancer detection were collected, summarized and organized to select representative and reliable research articles that matched the study's requirements. PubMed and Medline complete were used for systematic retrieval from 2008 to 2018. First, we set two keywords ('bladder cancer' and 'detection') for abstract retrieval, resulting in 2783 relevant English-language papers. Second, 297 full texts met the inclusion criteria by including the results of detection of bladder cancer with or without a clinical trial. We then used 'bladder cancer, detection' as abstracts and 'clinical trial, accuracy' as full articles that had been reviewed. After all exclusions, 44 relevant articles were obtained. The main exclusion criterion was that the tests had not been used for clinical diagnosis. Other publications regarding urinary problems and other cancers were also excluded. The flowchart for the entire article search is presented in Figure 1.

All diagnostic methods for clinical use have their own pros and cons; therefore, it becomes a top priority to find a method of detection and diagnosis of bladder cancer that is characterized by high sensitivity, high specificity, low cost, non-invasive nature, ease of use and good reproducibility. Sensitivity and specificity are both widely used to portray the results of diagnoses in the medical diagnosis field. Specificity examines healthy subjects who show negative results, and sensitivity examines those with cancer who show true positive results. Therefore, the use of sensitivity and specificity to compare several diagnostic methods can provide more reference information for the patients. In this study, we compared the diagnostic accuracy of various methods, so any article without information regarding such measures was excluded. In the end, we used 21 articles from PubMed and 23 articles from Medline complete for analysis.

\section{Results and Discussion}

This section summarizes the bladder cancer detection methods, their sensitivities and specificities and their advantages and disadvantages.

\subsection{Urine microscopy}

Urine microscopy serves as a crucial tool to determine several conditions that can affect the kidneys and the urinary tract. Nephrologists and pathologists are both responsible for microscopic examination of urine [13]. Urine samples should be acquired for microscopy in the relevant examining centre using an aseptic method. Patients have no risk of injury or bacterial infection (unless urine is collected via catheterization). However, this method also has some disadvantages. The sample may include debris such as bacteria and exudates from the lower urinary tract or genital tract. If there is an increase in bacteria in the urine, it is necessary to properly identify whether its origin is urethral pollution or urinary tract infection. Catheterization performed to collect urine may also induce trauma to the urinary tract [14]. Table 1 shows a review of the sensitivity and specificity of urine microscopy. 


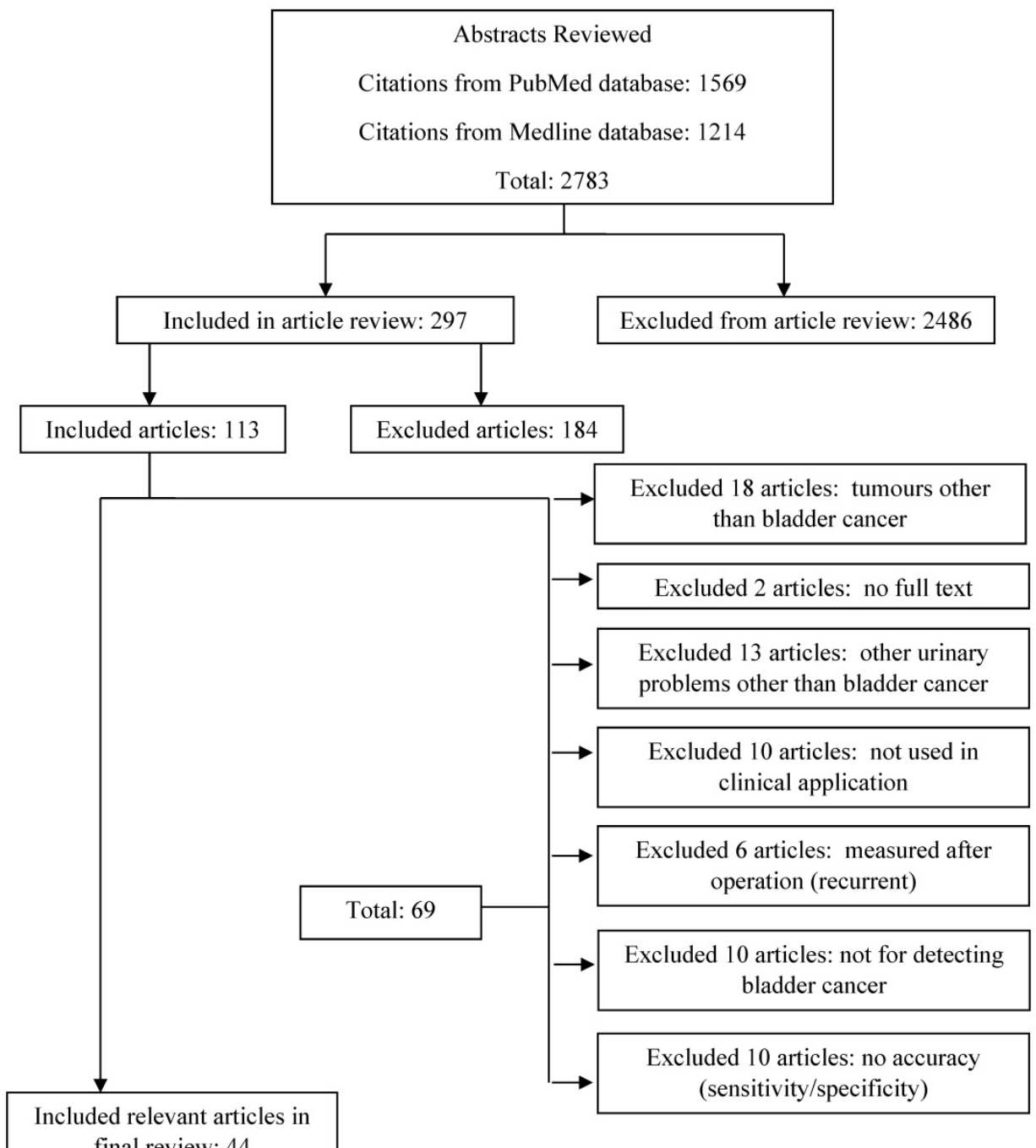

Figure 1. Flowchart of literature search results using Medline complete and PubMed from 2008 to 2018.

Table 1. Sensitivity and specificity of urine microscopy for bladder cancer

\begin{tabular}{llll}
\hline Authors & Year & Sensitivity/specificity (\%) & References \\
\hline Nataraju et al. & 2018 & $87 / 92$ & {$[15]$} \\
Becker et al. & 2016 & $87.5 /$ NA & {$[16]$} \\
Williams et al. & 2010 & $91 / 96$ & {$[17]$}
\end{tabular}

Table 2. Sensitivity and specificity of urine cytology for bladder cancer

\begin{tabular}{llll}
\hline Authors & Year & Sensitivity/specificity (\%) & References \\
\hline Kumar et al. & 2017 & $13.3 / 100$ & {$[18]$} \\
Lee et al. & 2015 & $86 / 73$ & {$[19]$} \\
Anai et al. & 2014 & $83 /$ NA & {$[20]$} \\
Hajdinjak & 2008 & $42 / 96$ & {$[21]$} \\
\hline
\end{tabular}

\subsection{Urine cytology}

Urinary cytology is performed under a microscope to screen the urine of a patient with bladder cancer for cancer cells. If the sample includes abnormal cells, the doctor will ask the patient for another sample. Table 2 shows a review of the sensitivity and specificity of urine cytology. Based on the review, Table 3 shows the advantages and disadvantages of the detection method.

Table 3. Advantages and disadvantages of urine cytology [22]

\begin{tabular}{|c|c|c|}
\hline Specimen Type & Advantages & Disadvantages \\
\hline Voided urine & $\begin{array}{l}\text { Non-invasive } \\
\text { No instrumentation artifact }\end{array}$ & $\begin{array}{l}\text { Low cellularity } \\
\text { Vaginal contamination } \\
\text { Poor preservation }\end{array}$ \\
\hline Catheterized & High cellularity & $\begin{array}{l}\text { Invasive } \\
\text { Instrumentation artifact } \\
\text { Poor preservation }\end{array}$ \\
\hline Bladder washing & $\begin{array}{l}\text { High cellularity } \\
\text { Good cell preservation }\end{array}$ & $\begin{array}{l}\text { Invasive } \\
\text { Instrumentation artifact }\end{array}$ \\
\hline Upper tract washing & $\begin{array}{l}\text { High cellularity } \\
\text { Good preservation } \\
\text { Selective sampling }\end{array}$ & $\begin{array}{l}\text { Invasive } \\
\text { Instrumentation artifact }\end{array}$ \\
\hline Brush cytology & Selective sampling & $\begin{array}{l}\text { Invasive } \\
\text { Air drying possible (if direct } \\
\text { smear) }\end{array}$ \\
\hline
\end{tabular}




\subsection{Urine markers}

Urine markers are a combined method for bladder cancer diagnosis. Although more than 30 urinary biomarkers are recognized to diagnose bladder disease, only a few can be used [23]. It is universally acknowledged that bladder cancer should be diagnosed with urine tests such as the UroVysion test, ImmunoCyt test or NMP-22 test. Each of these examinations is conducted by recognizing chemicals, proteins and changes in chromosomes in the urine [24]. Commercially available tests include:

- Urine cytology

- Fluorescence in situ hybridization (FISH)

- Nuclear matrix protein (NMP-22)

- BTA stat

- BTA TRAK

- ImmunoCyt/uCyt+

- CertNDx

- CxBladder

When surveying a marker's operation, researchers should consider the research population because it could have an influence on the operation of a marker at a later stage of the illness. Although the mark of the machine may be low, several markers have been subjected to focused research. Based on the review of urine markers and their sensitivity and specificity given in Table 4, it can be seen that the advantages of this method include its high sensitivity, greater number of choices, less pain and detection of low-grade tumours. In contrast, its disadvantages mainly include its high cost, invasive nature, complexity and high inter-observer variability [25].

Table 4. Sensitivity and specificity of urine markers for bladder cancer

\begin{tabular}{lll}
\hline Urine markers & \multicolumn{1}{c}{ Sensitivity/specificity $(\%)$} & References \\
\hline BTA TRAK & $72-99 / 12.1-78$ & {$[26-28]$} \\
BTA stat & $56-83 / 72-85.7$ & {$[27,29]$} \\
NMP22 & $51-100 / 73-90$ & {$[27,28]$} \\
UroVysion & $80-86 / 61-86$ & {$[21,30]$} \\
ImmunoCyt & $68.1-72.5 / 65.7-72.3$ & {$[31,32]$} \\
UBC & $53.8 / 97.2$ & {$[26]$} \\
TMPRSS2:ERGFusion & $45.4 / 34.8$ & {$[33]$} \\
\hline
\end{tabular}

Abbreviation: $\mathrm{UBC}=$ urinary bladder cancer antigen

\subsection{Cystoscopy}

This is the most vital test for diagnosing bladder cancer using cystoscope. Patients can undergo this test under local anaesthesia or general sedation. If tissue sampling is required, cystoscopy must take place under general anaesthesia [34]. Based on the review of the method and its sensitivity and specificity in Table 5, it can be seen that one advantage is that it is easily performed [35]. Every alternative method should be examined and evaluated with the doctor, who can confirm which choice will work best for the patients. However, this method has disadvantages; it might miss a small flat tumour, and it involves instrumentation and thus a risk of urethral injury, urinary tract infection and haematuria [36].

Table 5. Sensitivity and specificity of cystoscopy for bladder cancer

\begin{tabular}{|c|c|c|c|c|}
\hline Authors & Year & Method & Sensitivity/specificity (\%) & References \\
\hline Ciudin et al. & 2015 & Air cystoscopy & $88 / 97$ & {$[36]$} \\
\hline $\begin{array}{l}\text { Horstmann et } \\
\text { al. }\end{array}$ & 2014 & PDD cystoscopy & $92 / 57$ & [37] \\
\hline Shen et al. & 2012 & $\begin{array}{l}\text { NBI or WLI } \\
\text { cystoscopy }\end{array}$ & $\begin{array}{l}87.8 \text { / } 77.1 \text { (NBI) } \\
68.3 \text { / } 82.9 \text { (WLI) }\end{array}$ & [38] \\
\hline van Rhijn et al. & 2009 & Urethra-cystoscopy & $75 / 83$ & [39] \\
\hline Allam et al. & 2009 & Cystoscopy & $100 / 94.4$ & [40] \\
\hline
\end{tabular}

\section{$3.5 \mathrm{CT}$}

A computed tomography (CT) is not used for screening but is used for staging once bladder cancer is diagnosed via cystoscopy and biopsy or via transurethral resection. A CT urogram is an imaging test to examine the urethra system that uses $\mathrm{X}$ - rays to generate multiple images of a part of a subject's body (e.g., blood vessels, soft tissue); these images are then sent to a computer for reconstruction of detailed three-dimensional images [41]. The advantages of this method include: (1) it completely eliminates the superimposition of images of structures outside the area of interest; and (2) the statistics gained from one CT image, which comprises multiple contiguous or one helical scan, are considered images in the axial, coronal or sagittal planes, relying on the diagnostic task, which is seen as multi-planar reformatted imaging. The disadvantages of this method include: (1) a slight increase in the risk of cancer in later life via exposure to ionizing radiation (X-rays); (2) its use of higher doses of radiation than normal X-ray scanning makes the risks (while still small) greater than other types in general; and (3) injection of a contrast medium (dye) can lead to kidney insult or allergic reaction [42]. Table 6 shows a review of the CT scan method and its sensitivity and specificity.

Table 6. Sensitivity and specificity of CT scan for bladder cancer

\begin{tabular}{|c|c|c|c|c|}
\hline Authors & Year & Method & Sensitivity/specificity (\%) & References \\
\hline Lu et al. & 2012 & $\begin{array}{l}\mathrm{CT} \text { for staging or } \\
\text { restaging }\end{array}$ & $82 / 89$ & {$[43]$} \\
\hline $\begin{array}{l}\text { Harkirat et } \\
\text { al. }\end{array}$ & 2010 & $\begin{array}{l}\text { CT for restaging } \\
\text { CT for restaging }\end{array}$ & $\begin{array}{l}53.8 / 77.8 \\
86.7 / 100\end{array}$ & [44] \\
\hline $\begin{array}{l}\text { Swinnen et } \\
\text { al. }\end{array}$ & 2010 & $\begin{array}{l}\mathrm{CT} \text { for staging } \\
\mathrm{CT} \text { for staging }\end{array}$ & $\begin{array}{l}46 / 97 \\
46 / 92\end{array}$ & [45] \\
\hline Sadow et al. & 2008 & CT for detection & $79 / 94$ & {$[46]$} \\
\hline
\end{tabular}




\subsection{MR imaging}

Bladder cancer is staged mainly with magnetic resonance imaging (MRI), a form of tomography that uses a powerful magnetic resonance phenomenon to extract electromagnetic signals from the body and reconstruct body information [47]. Before starting the MRI scan, it is essential that any metal articles (e.g., watches, jewellery, piercings, etc.) be removed from the subject's body because metal can affect the image quality and hence alter the diagnosis [47]. Because no radiation process is involved in MRI, it presents no danger to individuals who are required to avoid radiation, such as pregnant women or children, and it is easy to perform. Scanning is carried out in an enclosed space, so individuals who are claustrophobic or are otherwise unable or unwilling to remain in an enclosed space may have trouble undergoing MRI. MRI scanners often makes significant noises and require large amounts of electric current, and their cost is usually high [48]. Table 7 shows a review of the MRI method and its sensitivity and specificity.

Table 7. Sensitivity and specificity of MRI for bladder cancer

\begin{tabular}{lllll}
\hline Authors & Year & Method & $\begin{array}{l}\text { Sensitivity/ } \\
\text { specificity (\%) }\end{array}$ & References \\
\hline Lee M et al. & 2017 & MRI for staging & $80.8 / 77.8$ & {$[49]$} \\
Daneshmand et al. & 2012 & DGE-MRI for staging & $87.5 / 91.5$ & {$[50]$} \\
Rajesh et al. & 2011 & MRI for staging & $78.2 / 93.3$ & {$[51]$} \\
Watanabe et al. & 2009 & MRI for staging & $70 / 79$ & {$[52]$} \\
\hline
\end{tabular}

Abbreviation: DGE=dynamic glucose-enhanced

\subsection{Combined method - Urine Markers and Urine Cytology}

A combined method diagnosis system combines one or more methods. This combination will increase the accuracy of detecting cancer or other problems in the human body. The combined use of urine markers and urine cytology can improve bladder cancer detection. Table 8 compares the sensitivity and specificity of various combined urine markers and urine cytology methods.

Table 8. Sensitivity and Specificity of urinary markers combined urine cytology

\begin{tabular}{lll}
\hline Method & Sensitivity/ Specificity (\%) & References \\
\hline NMP 22 + Cytology & $73-94 / 84-90$ & {$[53,54]$} \\
BTA Stat + Cytology & $91-93 / 78-90$ & {$[53,54]$} \\
BTA TRAK + Cytology & $68-72 / 53-75$ & {$[53,55]$} \\
FDP + Cytology & $68-89 / 50-78$ & {$[53,56]$} \\
ImmunoCyt + Cytology & $72.8-90 / 64.4-78$ & {$[31,32,54]$} \\
UroVysion FISH + Cytology & $61.9-72 / 83-89.7$ & {$[21,57]$} \\
\hline
\end{tabular}

Abbreviation: $\mathrm{FDP}=$ fibrinogen degradation products

All in all, for the selection of the bladder tumour marker to be economically affordable, the medical equipment must check the bladder pathological area completely [58]. Screening and examination methods that are powerful and specific should be made immediately and completely available to doctors. However, urine cytology is sometimes affected by lower efficiency with voided quality grades [39].

\section{Conclusion}

The methods considered in this study clearly have their respective strengths. The sensitivity and specificity data in the articles were collected from various patients. We can understand the higher detection performance with the methods used. The best accuracy can also be compared between the single and combined methods. Table 9 shows the methods and the percentage range of sensitivity and specificity for each method. It can be concluded that the methods for detecting bladder cancer can be used with different modes of varying characteristics. Some of the methods are highly accurate but some are not. Nevertheless, each method has its own advantages and disadvantages.

Table 9. The percentage range of sensitivity and specificity in different detection methods

\begin{tabular}{ll}
\hline Methods & Sensitivity/Specificity (\%) \\
\hline Urine microscopy & $87-91 / 92-96$ \\
Urine cytology & $13.3-86 / 73-100$ \\
Urine markers & $45.4-100 / 12.1-97.2$ \\
Cystoscopy & $68.3-100 / 57-97$ \\
CT & $46-86.7 / 77.8-100$ \\
MRI & $78.2-87.5 / 77.8-93.3$ \\
Urine Markers + Urine Cytology & $61.9-94 / 50-90$ \\
\hline
\end{tabular}

Table 9 shows that urine makers and cystoscopy have the same highest sensitivity and the highest specificity of $97.2 \%$ and $97 \%$, respectively. The table also shows that of the combined methods, the highest sensitivity of $94 \%$ and the highest specificity of $90 \%$ are found in urine markers and urine cytology. Bladder growth is caused by a combination of cancer-causing agents and might have a variable history. Although superficial bladder tumours occur more often, they have a tendency to progress. Each examination should ensure proper diagnosis, arrangement and evaluation.

\section{Acknowledgments}

The authors would like to thank University of Malaya for financially supporting this research under Postgraduate Research Grant (PPP grant number: PG056-2015A).

\section{Authors' contributions}

Chao-Zhe Zhu wrote the manuscript. Hua-Nong Ting, Kwan-Hoong Ng and Teng-Aik Ong revised the manuscript. 


\section{Ethics and consent}

This review is comprised of articles which included established ethical clearance procured for the research, or if that was not apparent, the informed consent process was described clearly within the article thus implying that the statement of ethical consent need not be published directly, merely accompanying the submission of the article to prove the ethical quality. Therefore, this review examined and included articles if it was clear that the studies were performed in an ethical manner.

\section{Paper Context}

Bladder cancer is the most common malignant tumour in urinary system, which is high incidence and recurrence rate. This article reviews the most recent common research and its advantages and disadvantages. The results of this review can positively help to identify the accurate method for detecting cancer and can be further improved for future research works.

\section{Competing Interests}

The authors have declared that no competing interest exists.

\section{References}

1. Bray F, Ferlay J, Soerjomataram I, Siegel RL, Torre LA, Jemal A. Global cancer statistics 2018: GLOBOCAN estimates of incidence and mortality worldwide for 36 cancers in 185 countries. CA: a cancer journal for clinicians. 2018; 68: 394-424

2. Kim YS, Maruvada P, Milner JA. Metabolomics in biomarker discovery: future uses for cancer prevention. Future Oncology. 2008; 4.

3. Jemal A, Bray F, Center MM, Ferlay J, Ward E, Forman D. Global cancer statistics. CA: a cancer journal for clinicians. 2011; 61: 69-90

4. Siegel R, Naishadham D, Jemal A. Cancer statistics for hispanics/latinos, 2012. CA: a cancer journal for clinicians. 2012; 62: 283-98.

5. Witjes JA, Compérat E, Cowan NC, De Santis M, Gakis G, Lebret T, et al. EAU guidelines on muscle-invasive and metastatic bladder cancer: summary of the 2013 guidelines. European urology. 2014; 65: 778-92.

6. Burger M, Catto JW, Dalbagni G, Grossman HB, Herr H, Karakiewicz P, et al. Epidemiology and risk factors of urothelial bladder cancer. European urology. 2013; 63: 234-41.

7. Knowles MA, Hurst CD. Molecular biology of bladder cancer: new insights into pathogenesis and clinical diversity. Nature reviews cancer. 2015; 15: 25

8. Babjuk M, Burger M, Zigeuner R, Shariat SF, van Rhijn BW, Comperat E, et al. EAU guidelines on non-muscle-invasive urothelial carcinoma of the bladder: update 2013. European urology. 2013; 64: 639-53.

9. Ding W, Chen Z, Gou Y, Sun C, Xu K, Tan J, et al. Are EORTC risk tables suitable for Chinese patients with non-muscle-invasive bladder cancer? Cancer epidemiology. 2014; 38: 157-61.

10. Jacobs BL, Lee CT, Montie JE. Bladder cancer in 2010: how far have we come? CA: a cancer journal for clinicians. 2010; 60: 244-72

11. Kamat AM, Witjes JA, Brausi M, Soloway M, Lamm D, Persad R, et al. Defining and treating the spectrum of intermediate risk nonmuscle invasive bladder cancer. The journal of urology. 2014; 192: 305-15.

12. Ye F, Wang L, Castillo-Martin M, McBride R, Galsky MD, Zhu J, et al. Biomarkers for bladder cancer management: present and future. American journal of clinical and experimental urology. 2014; 2 : 1 .

13. Perazella MA. The urine sediment as a biomarker of kidney disease. American journal of kidney diseases. 2015; 66: 748-55.

14. Vasudevan R. Urinary tract infection: an overview of the infection and the associated risk factors. Journal of microbiology \& experimentation. 2014; 1: 00008 .

15. Nataraju G, Gayathri MN, et al. Compendium of Urinalysis-Urine Reagent Strips and Microscopy. Journal of medical science and clinial research. 2018; 6 .

16. Becker GJ, Garigali G, Fogazzi GB. Advances in urine microscopy. American journal of kidney diseases. 2016; 67: 954-64.
17. Williams GJ, Macaskill P, Chan SF, Turner RM, Hodson E, Craig JC. Absolute and relative accuracy of rapid urine tests for urinary tract infection in children: a meta-analysis. The Lancet infectious diseases. 2010; 10: 240-50.

18. Kumar N, Talwar R, Nandy P. Efficacy of voided urinary cytology and ultrasonography compared to cystoscopy in the detection of urinary bladder cancer. African journal of urology. 2017; 23: 192-6.

19. Lee P, Owens C, Fischer A. Sensitivity of Urine Cytology for High Grade Urothelial Carcinoma and Explanations for False-Negative Cytologies. Journal of the American society of cytopathology. 2015; 6: S19-S20.

20. Anai S, Nakai Y, Miyake M, Tanaka N, Hirao Y, Fujimoto K. The sensitivity of the novel fluorescent urine cytology using 5-aminolevulinic acid (5-ALA) is higher than the conventional urine cytology. The journal of Urology. 2014; 191.

21. Hajdinjak T. UroVysion FISH test for detecting urothelial cancers: meta-analysis of diagnostic accuracy and comparison with urinary cytology testing. Urologic oncology: seminars and original investigations. 2008; 26: 646-51.

22. Cibas ES, Ducatman BS. Cytology E-Book: diagnostic principles and clinical correlates. Philadelphia PA, U.S.A: Elsevier Health Sciences Publisher. 2013.

23. Schiffer E, Vlahou A, Petrolekas A, Stravodimos K, Tauber R, Geschwend JE, et al. Prediction of muscle-invasive bladder cancer using urinary proteomics. Clinical cancer research. 2009; 15: 4935-43.

24. Council C. Understanding bladder cancer: A guide for people with cancer, their families and friends. Australia: Cancer Council Australia Publisher; 2018

25. Vrooman OP, Witjes JA. Urinary markers in bladder cancer. European urology. 2008; 53: 909-16.

26. Babjuk M, Soukup V, Pešl M, Koštíŕová M, Drncová E, Smolová H, et al. Urinary cytology and quantitative BTA and UBC tests in surveillance of patients with pTapT1 bladder urothelial carcinoma. Urology. 2008; 71: 718-22.

27. Smith ZL, Guzzo TJ. Urinary markers for bladder cancer. F1000prime reports 2013; 5 .

28. Tsui $\mathrm{KH}$, Chen SM, Wang TM, Juang HH, Chen CL, Sun GH, et al. Comparisons of voided urine cytology, nuclear matrix protein-22 and bladder tumor associated antigen tests for bladder cancer of geriatric male patients in Taiwan, China. Asian journal of andrology. 2007; 9: 711-5.

29. Raitanen M-P, Group F. The role of BTA stat Test in follow-up of patients with bladder cancer: results from FinnBladder studies. World journal of urology. 2008; 26: 45-50.

30. Pajor G, Somogyi L, Melegh B, Alpar D, Kajtar B, Farkas L, et al. Urovysion: Considerations on modifying current evaluation scheme, including immunophenotypic targeting and locally set, statistically derived diagnostic criteria. Cytometry part A. 2011; 79: 375-82.

31. He H, Han C, Hao L, Zang G. ImmunoCyt test compared to cytology in the diagnosis of bladder cancer: A meta-analysis. Oncology letters. 2016; 12: 83-8.

32. Comploj E, Mian C, Ambrosini-Spaltro A, Dechet C, Palermo S, Trenti E, et al. $\mathrm{uCyt}+$ /ImmunoCyt and cytology in the detection of urothelial carcinoma. Cancer cytopathology. 2013; 121: 392-7.

33. Nguyen P-N, Violette P, Chan S, Tanguay S, Kassouf W, Aprikian A, et al. A panel of TMPRSS2: ERG fusion transcript markers for urine-based prostate cancer detection with high specificity and sensitivity. European urology. 2011; 59: 407-14.

34. Victoria CC. Bladder cancer. Melbourne, Australia: Cancer Council Victoria. Revised 10 Novermber 2018. https://www.cancervic.org.au/cancerinformation/types-of-cancer/bladder_cancer/diagnosing-bladder-cancer.ht

35. Lokeshwar VB, Merseburger AS, Hautmann SH. Bladder Tumors: Molecular Aspects and Clinical Management. New York, U.S.A: Springer Science \& Business Media Publisher. 2010.

36. Ciudin A, Diaconu MG, Gosalbez D, Peri L, Garcia-Cruz E, Franco A, et al. Air cystoscopy is superior to water cystoscopy for the diagnosis of active hematuria. The journal of urology. 2013; 190: 2097-101.

37. Horstmann M, Banek S, Gakis G, Todenhöfer $T$, Aufderklamm S, Hennenlotter J, et al. Prospective evaluation of fluorescence-guided cystoscopy to detect bladder cancer in a high-risk population: results from the UroScreen-Study. SpringerPlus. 2014; 3: 24.

38. Shen Y-J, Zhu Y-P, Ye D-W, Yao X-D, Zhang S-L, Dai B, et al. Narrow-band imaging flexible cystoscopy in the detection of primary non-muscle invasive bladder cancer: a "second look" matters? International urology and nephrology. 2012; 44: 451-7.

39. van Rhijn BW, van der Poel HG, van der Kwast TH. Cytology and urinary markers for the diagnosis of bladder cancer. European urology supplements. 2009; 8: 536-41.

40. Allam A, Hathout B, Alnusif S. Can use the NMP22 BladderChek Decrease the Frequency of Cystoscopy in the Follow up of Patients with Bladder Carcinoma? International journal of nephrology and urology. 2009; 1: 51-5.

41. Bélanger C, Chartrand-Lefebvre C, Soulez G, Faughnan ME, Tahir MR, Giroux $\mathrm{M}-\mathrm{F}$, et al. Pulmonary arteriovenous malformation (PAVM) reperfusion after percutaneous embolization: sensitivity and specificity of non-enhanced CT. European journal of radiology. 2016; 85: 150-7.

42. Sankowski AJ, Łebkowska UM, Ćwikła J, Walecka I, Walecki J. The comparison of efficacy of different imaging techniques (conventional radiography, ultrasonography, magnetic resonance) in assessment of wrist joints and metacarpophalangeal joints in patients with psoriatic arthritis. Polish journal of radiology. 2013; 78: 18 . 
43. Lu Y-Y, Chen J-H, Liang J-A, Wang H-Y, Lin C-C, Lin W-Y, et al. Clinical value of FDG PET or PET/CT in urinary bladder cancer: a systemic review and meta-analysis. European journal of radiology. 2012; 81: 2411-6.

44. Harkirat S, Anand S, Jacob M. Forced diuresis and dual-phase 18F-fluorodeoxyglucose-PET/CT scan for restaging of urinary bladder cancers. The Indian journal of radiology \& imaging. 2010; 20: 13.

45. Swinnen $\mathrm{G}$, Maes A, Pottel $\mathrm{H}$, Vanneste A, Billiet $\mathrm{I}$, Lesage $\mathrm{K}$, et al. FDG-PET/CT for the preoperative lymph node staging of invasive bladder cancer. European urology. 2010; 57: 641-7.

46. Sadow CA, Silverman SG, O'Leary MP, Signorovitch JE. Bladder cancer detection with CT urography in an Academic Medical Center. Radiology. 2008; 249: 195-202.

47. Huettel SA, Song AW, McCarthy G. Functional magnetic resonance imaging. Sunderland, Massachusetts U.S.A.: Sinauer Associates, Inc Publisher. 2004

48. Katti G, Ara SA, Shireen A. Magnetic resonance imaging (MRI)-A review. International journal of dental clinics. 2011;3.

49. Lee M, Shin S-J, Oh YT, Jung DC, Cho NH, Choi YD, et al. Non-contrast magnetic resonance imaging for bladder cancer: fused high $b$ value diffusion-weighted imaging and T2-weighted imaging helps evaluate depth of invasion. European radiology. 2017; 27: 3752-8.

50. Daneshmand Siamak, Hamed Ahmadi, Ly N. Huynh, Dobos. N. Preoperative staging of invasive bladder cancer with dynamic gadolinium-enhanced magnetic resonance imaging: results from a prospective study. Urology. 2012; 80: 1313-8.

51. Rajesh A, Sokhi H, Fung R, Mulcahy K, Bankart M. Bladder cancer: evaluation of staging accuracy using dynamic MRI. Clinical radiology. 2011; 66: 1140-5.

52. Watanabe H, Kanematsu M, Kondo H, Goshima S, Tsuge Y, Onozuka M, et al. Preoperative $\mathrm{T}$ staging of urinary bladder cancer: does diffusion-weighted MRI have supplementary value? American journal of roentgenology. 2009; 192: 1361-6.

53. Sullivan PS, Chan JB, Levin MR, Rao J. Urine cytology and adjunct markers for detection and surveillance of bladder cancer. American journal of translational research. 2010; 2: 412.

54. Yafi FA, Brimo F, Steinberg J, Aprikian AG, Tanguay S, Kassouf W. Prospective analysis of sensitivity and specificity of urinary cytology and other urinary biomarkers for bladder cancer. Urologic oncology: seminars and original investigations. 2015; 33: 66.e25-66.e31.

55. Miyake M, Goodison S, Rizwani W, Ross S, Grossman HB, Rosser CJ. Urinary BTA: indicator of bladder cancer or of hematuria. World journal of urology. 2012; 30: 869-73.

56. Razzaghi M, Hosseini MM, Rezaei A, Rezaei L, Javanmard B, Moradi A. 86: Sensitivity and specifity of the urinary FDP in diagnosis of transitional cell carcinoma of bladder. Indian journal of urology. 2008; 24 (Suppl 2):s81.

57. Dimashkieh H, Wolff DJ, Smith TM, Houser PM, Nietert PJ, Yang J. Evaluation of urovysion and cytology for bladder cancer detection: a study of 1835 paired urine samples with clinical and histologic correlation. Cancer cytopathology. 2013; 121: 591-7.

58. Ward DG, Baxter L, Gordon NS, Ott S, Savage RS, Beggs AD, et al. Multiplex PCR and next generation sequencing for the non-invasive detection of bladder cancer. PloS one. 2016; 11: e0149756. 